\title{
Feasibility study of personalized peptide vaccination for advanced non-small cell lung cancer patients who failed two or more treatment regimens
}

\author{
TEPPEI YAMADA ${ }^{1,3}$, YASUHIRO TERAZAKI ${ }^{2}$, SHINJIRO SAKAMOTO $^{1}$, KOICHI YOSHIYAMA $^{2}$, \\ SATOKO MATSUEDA ${ }^{4,5}$, NOBUKAZU KOMATSU ${ }^{1}$, KAYOKO WAKI $^{4}$, AKIRA YAMADA ${ }^{4}$, \\ AKIHIKO KAWAHARA ${ }^{6}$, MASAYOSHI KAGE ${ }^{4,6}$, SHUNICHI SUGAWARA ${ }^{7}$, YUICHI YAMASHITA ${ }^{3}$, \\ TETSURO SASADA $^{1,5}$, SHINZO TAKAMORI ${ }^{2}$ and KYOGO ITOH ${ }^{1,5}$

\begin{abstract}
Departments of ${ }^{1}$ Immunology and Immunotherapy and ${ }^{2}$ Surgery, Kurume University School of Medicine, Kurume; ${ }^{3}$ Department of Gastroenterological Surgery, Fukuoka University School of Medicine, Fukuoka;

${ }^{6}$ Department of Diagnostic Pathology, Kurume University Hospital, Kurume, Fukuoka;

${ }^{7}$ Department of Pulmonary Medicine, Sendai Kousei Hospital, Sendai, Miyagi, Japan
\end{abstract} \\ ${ }^{4}$ Research Center for Innovative Cancer Therapy and ${ }^{5}$ Cancer Vaccine Center, Kurume University, Kurume;
}

Received July 2, 2014; Accepted August 19, 2014

DOI: $10.3892 / \mathrm{ijo} .2014 .2699$

\begin{abstract}
The prognosis of non-small cell lung cancer (NSCLC) patients who failed two or more treatment regimens remains very poor. We conducted a phase II study to explore the feasibility of personalized peptide vaccination (PPV), in which peptides are selected and administered based on the preexisting host immunity before vaccination, as a third or more line treatment in advanced NSCLC patients who failed two or more regimens. Among 57 patients enrolled, 23 or 16 patients received PPV with chemotherapy or targeted therapy, respectively, whereas 18 patients received PPV alone. A maximum of four HLA-matched peptides showing higher peptide-specific
\end{abstract}

Correspondence to: Dr Teppei Yamada, Department of Immunology and Immunotherapy, Kurume University School of Medicine, 67 Asahi-machi, Kurume 830-0011, Japan

E-mail: yamatetsu2013@gmail.com

Dr Kyogo Itoh, Cancer Vaccine Center, Kurume University, 155-1 Kokubu-machi, Kurume, Fukuoka 839-0863, Japan

E-mail: kyogo@med.kurume-u.ac.jp

Abbreviations: NSCLC, non-small cell lung cancer; PPV, personalized peptide vaccination; OS, overall survival; IHC, immunohistochemistry; SCC, squamous cell carcinoma; ECOG, Eastern Cooperative Oncology Group; HLA, human leukocyte antigen; NCI-CTC, National Cancer Institute Common Terminology Criteria for Adverse Events; CTL, cytotoxic T lymphocyte; IFN, interferon; PBMCs, peripheral blood mononuclear cells; SAEs, severe adverse events; MST, median survival time

Key words: non-small cell lung cancer, peptide vaccine, personalized medicine, clinical study, third line therapy
IgG responses in pre-vaccination plasma were selected from 31 pooled peptide candidates applicable for patients with HLA-A2, -A24, -A3 supertypes, and/or -A26, followed by subcutaneous administration. No severe adverse events related to PPV were observed. Median survival time was 692, 468, or 226 days in the group of PPV/chemotherapy, PPV/targeted therapy, or PPV alone, respectively. CTL responses to the vaccinated peptides became detectable after vaccination in 58,50 , or $42 \%$ of patients in each of these three groups, respectively. In contrast, peptide-specific IgG responses after vaccination augmented in 55, 75, or $62 \%$ of patients in each of these groups, respectively. These results suggest the feasibility of PPV for heavily treated advanced NSCLC patients from the view of both immunological responses and safety. Therefore, further evaluation of PPV by prospective randomized trial is warranted for a third or fourth line treatment of advanced NSCLC.

\section{Introduction}

Lung cancer is the leading cause of cancer-related deaths globally, and non-small cell lung cancer (NSCLC) is the most common type, observed in approximately $85 \%$ of patients, making it a major global public health concern $(1,2)$. Despite dramatic advances in the treatment of NSCLC over the last two decades, most of the patients experience disease progression and succumb to the disease. Since the prognosis of refractory NSCLC patients who failed two or more treatment regimens remains very poor (3-7), development of newer therapeutic approaches are needed. One of the new approaches might be the blockade of T cell inhibition mediated by checkpoint molecules, such as CTLA-4, PD-1, and PD-L1 in NSCLC patients (8-11). The other might be a personalized approach, and we have developed a novel regime of personalized peptide vaccination (PPV), in which peptides are selected and administered 
based on the pre-existing host immunity before vaccination (12-17). PPV could have the potential to prolong overall survival (OS), but not progression-free survival, in advanced cancer patients who failed standard chemotherapy (12-16). We also reported that high level of plasma $\mathrm{C}$-reactive protein was a significant predictor of unfavorable OS in refractory NSCLC patients (17). In the present study, we investigated the feasibility of PPV as a third or fourth line therapy for NSCLC patients.

\section{Patients and methods}

Immunohistochemistry (IHC). Expression of 15 vaccine antigens, from which the peptides were derived, was examined by IHC in primary cancer tissues of 20 non-vaccinated NSCLC patients [10 adenocarcinoma and 10 squamous cell carcinoma (SCC)] that were obtained at the time of radical operation. Paraffin-embedded tissue samples were cut into 4- $\mu \mathrm{m}$ sections, and examined on a coated slide glass. Detailed methods including antibodies used for IHC were previously described (15).

Patients. Patients diagnosed as advanced NSCLC patients who failed two or more treatment regimens were eligible to this study. All patients were required to have been diagnosed as stage IIIB, IV or recurrent at the time of entry. They had to show positive $\mathrm{IgG}$ responses to at least two of the 31 different vaccine candidate peptides, as reported previously (13-17). Other inclusion criteria were as follows: age between 20 and 80 years; an Eastern Cooperative Oncology Group (ECOG) performance status of 0 or 1 at the time of first visit; positive status for human leukocyte antigen (HLA)-A2, -A24, -A3 supertypes (A3, A11, A31, or A33), or -A26 types; life expectancy of $\geq 12$ weeks; and adequate hematologic, hepatic, and renal function. Exclusion criteria included pulmonary, cardiac, or other systemic diseases; an acute infection; a history of severe allergic reactions; pregnancy or nursing; and other inappropriate conditions for enrollment as judged by clinicians. The protocol was approved by the Kurume University Ethics Committee and registered in the UMIN Clinical Trials Registry (UMIN nos. 1482, 1839 and 2984). All patients were given a full explanation of the protocol and provided their informed consent before enrollment. Two patients whose performance status were evaluated as 2 at the time of 1st vaccination (two weeks after the first visit), were excluded from this study, while three patients who did not agree to combined chemotherapy or targeted therapy regardless of their tolerability were also excluded from this study.

Clinical protocol. This was a phase II study to evaluate the safety, immunological responses, and clinical benefits from a view of OS in heavily treated advanced NSCLC patients under PPV. Thirty-one peptides were employed for vaccination [12 peptides for HLA-A2, 16 peptides for HLA-A24, 9 peptides for HLA-A3 supertypes (-A3, -A11, -A31, and -A33), and 4 peptides for HLA-A26] as reported previously (13-17). These peptides were prepared under the condition of Good Manufacturing Practice by the PolyPeptide Laboratories (San Diego, CA, USA) and American Peptide Co. (Vista, CA, USA). Peptides for vaccination to individual patients were selected in consideration of the pre-existing host immunity before vaccination, as assessed by the titers of IgG specific to each of the 31 different vaccine candidates $(18,19)$. A maximum of 4 peptides ( $3 \mathrm{mg} / \mathrm{each}$ peptide), which were selected based on the results of HLA typing and peptide-specific IgG titers, were subcutaneously administered with incomplete Freund's adjuvant (Montanide ISA51; Seppic, Paris, France) once a week for 6 consecutive weeks (protocol nos. 1482 and 1839), or once a week for 4 consecutive weeks followed by biweekly administration 4 times (protocol no. 2984), as the 1st cycle. After the 1st cycle of vaccinations, up to 4 antigen peptides that were re-selected according to the titers of peptide-specific IgG were administered biweekly for 6 or 8 times, respectively. After the 2 nd cycle of vaccinations, up to 4 antigen peptides that were re-selected again were administered every 4 weeks until 24th vaccination. During the PPV, patients received combination chemotherapy or targeted therapy (gefetinib, erlotinib, or crizotinib), unless they were unable to tolerate either therapy. Adverse events were monitored according to the National Cancer Institute Common Terminology Criteria for Adverse Events version 3.0 (NCI-CTC Ver. 3.0). Complete blood counts and serum biochemistry tests were performed before and after each cycle of vaccinations.

Measurement of IgG and cytotoxic T lymphocyte (CTL) responses. Humoral immune responses specific to each of the 31 peptide candidates were determined by peptide-specific IgG levels using the Luminex system (Luminex, Austin, TX, USA), as previously reported (13-20). If the titers of peptide-specific IgG to at least one of the vaccinated peptides at the end of 1st cycle were $>2$-fold higher than those in the pre-vaccination plasma, the changes were considered to be significant as previously reported (13-18). CTL responses specific to the vaccinated peptides were evaluated by interferon (INF)- $\gamma$ ELISPOT using peripheral blood mononuclear cells (PBMCs) before and at the end of 1st cycle as previously reported (13-18). As a control, CTL responses specific to CEF peptides (Mabtech, Cincinnati, OH, USA), a mixture of virusderived CTL epitopes, were also examined.

Statistical analyses. All data were analyzed according to a pre-established plan. Comparison of each group was carried out by ANOVA test. OS was calculated from the first day of peptide vaccination until the date of death or the last date when the patient was known to be alive. The survival analysis was performed with the Kaplan-Meier method, and a comparison of the survival curves was performed with the log-rank test. If $\mathrm{p}$-value was $<0.05$, it was considered as statistically significant. All statistical analyses were conducted using the JMP version 10 (SAS Institute Inc., Cary, NC, USA).

\section{Results}

Immunohistochemical analysis (IHC). The expression of 15 vaccine antigens for PPV was examined in 20 nonvaccinated NSCLC tissues (10 adenocarcinoma and $10 \mathrm{SCC}$ ). Representative results are shown in Fig. 1 (adenocarcinoma) and Fig. 2 (SCC). Twelve of 15 vaccine antigens were expressed at different frequencies in NSCLC tissues, as follows; Cyp-B:9/10, EGF-R:9/10, EZH2:9/10, HNRPL:10/10, 
СурB

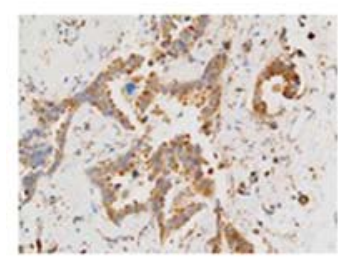

p56Lck

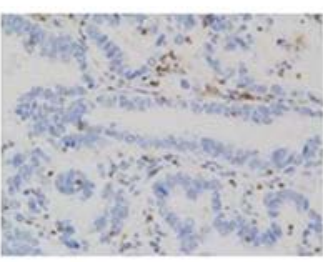

SART2

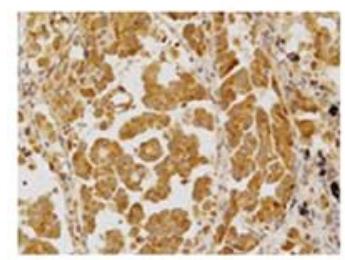

EGFR

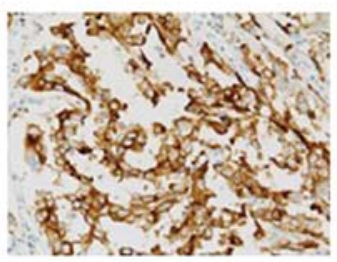

ppMAPkkk

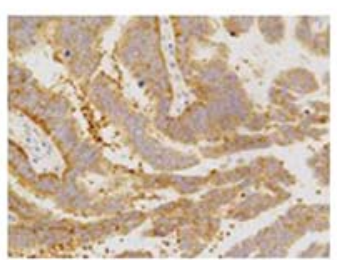

SART3

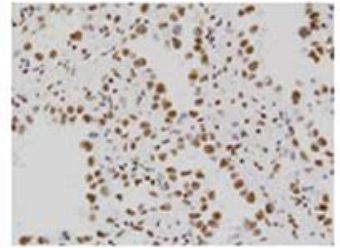

$\mathrm{EZH} 2$

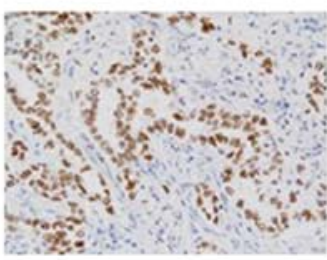

MRP3

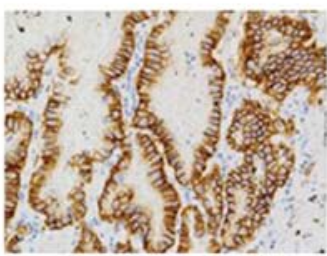

UBE2V

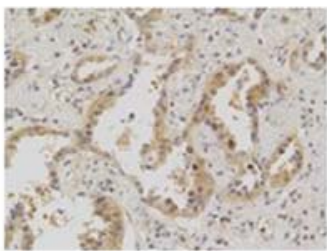

HNRPL

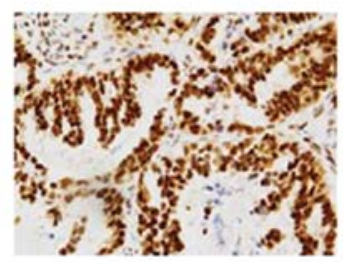

PTHrP

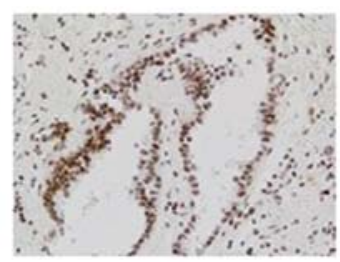

WHSC2

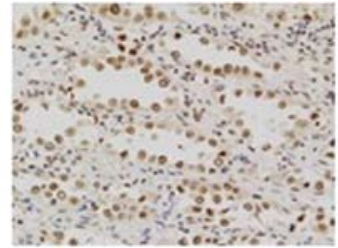

Figure 1. Expressions of vaccine antigen in lung adenocarcinoma tissues. Expression of 12 vaccine antigens, from which the peptides were derived, was examined by IHC in primary cancer tissues of 10 non-vaccinated lung adenocarcinoma patients. Representative results are shown (x400). The data of three prostate-related antigens, PAP, PSA and PSMA, are not shown.

СурB

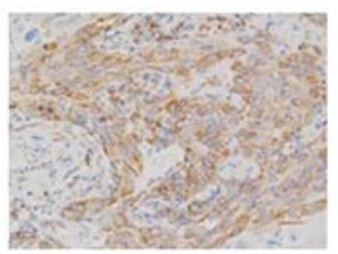

p56Lck

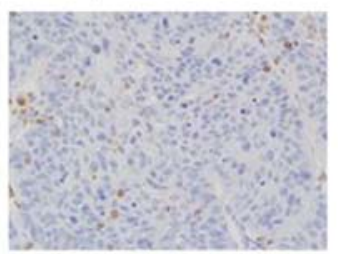

SART2

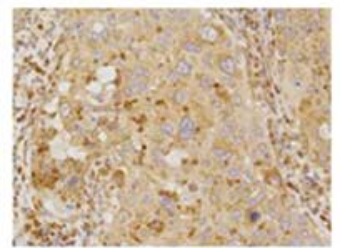

EGFR

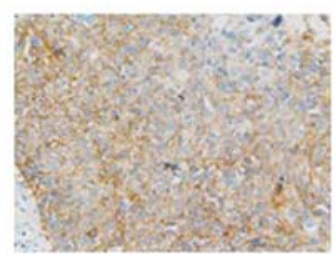

ppMAPkkk

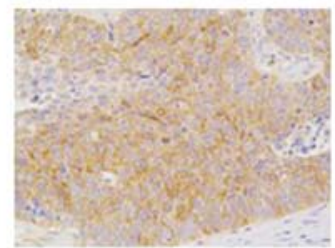

SART3

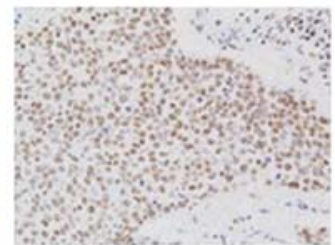

EZH2

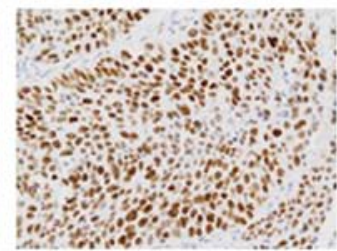

MRP3

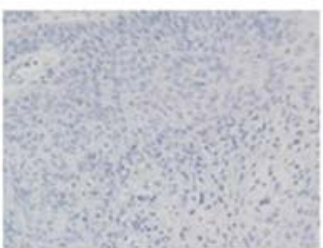

UBE2V

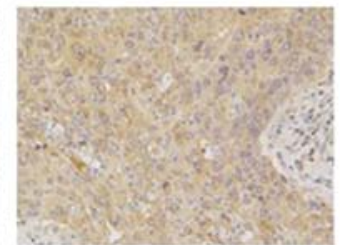

HNRPL

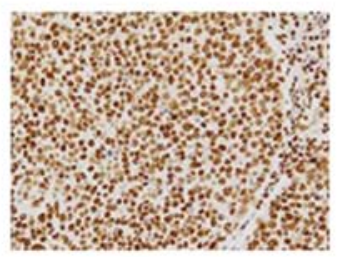

PTHrP

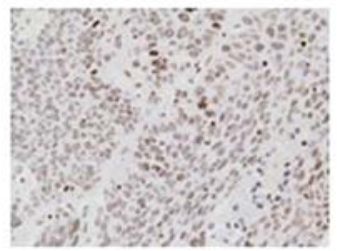

WHSC2

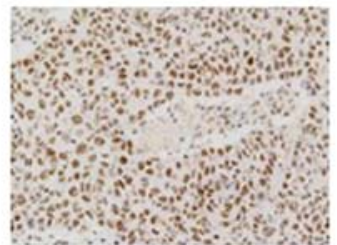

Figure 2. Expressions of vaccine antigen in lung SCC tissues. Expression of 12 vaccine antigens, from which the peptides were derived, was examined by IHC in primary cancer tissues of 10 non-vaccinated lung SCC patients. Representative results are shown (x400). The data of three prostate-related antigens, PAP, PSA and PSMA, are not shown. 
Table I. The patient characteristics.

\begin{tabular}{|c|c|c|c|c|c|}
\hline & $\begin{array}{l}\text { Overall } \\
(n=57)\end{array}$ & $\begin{array}{l}\text { PPV/chemotherapy } \\
\qquad(n=23)\end{array}$ & $\begin{array}{l}\text { PPV/targeted therapy } \\
\qquad(\mathrm{n}=16)\end{array}$ & $\begin{array}{l}\text { PPV alone } \\
\quad(n=18)\end{array}$ & p-value ${ }^{a}$ \\
\hline Age & & & & & 0.010 \\
\hline Median (range) & $64(37-77)$ & $64(37-77)$ & $57.5(42-75)$ & $67(54-76)$ & \\
\hline Sex & & & & & 0.107 \\
\hline Male/female & $27 / 30$ & $13 / 10$ & $4 / 12$ & $10 / 8$ & \\
\hline Performance status & & & & & 0.079 \\
\hline $0 / 1$ & $25 / 32$ & $12 / 11$ & $9 / 7$ & $4 / 14$ & \\
\hline Histopathology & & & & & 0.344 \\
\hline Adenocarcima & 47 & 21 & 12 & 14 & \\
\hline Others & 10 & 2 & 4 & 4 & \\
\hline Stage & & & & & 0.838 \\
\hline IIIB/IV/recurrence & $7 / 27 / 23$ & $3 / 11 / 9$ & $1 / 7 / 8$ & $3 / 9 / 6$ & \\
\hline \multicolumn{6}{|l|}{ HLA type } \\
\hline HLA-A24 & 34 & 12 & 12 & 10 & 0.329 \\
\hline HLA-A2 & 22 & 8 & 7 & 7 & 0.852 \\
\hline Lymphocyte count & & & & & 0.647 \\
\hline Median (range) & $1,480(1,014-3,399)$ & $1,370(1,014-2,653)$ & $1,475(1,058-3,192)$ & $1,524(1,032-3,399)$ & \\
\hline \multicolumn{6}{|l|}{ No. of previous treatment } \\
\hline regimen & & & & & 0.076 \\
\hline Median (range) & $3(2-12)$ & $4(2-9)$ & $3(2-8)$ & $4(2-12)$ & \\
\hline Time of peptide vaccination & & & & & 0.093 \\
\hline Median (range) & $11(2-24)$ & $13(2-24)$ & $13(6-24)$ & $8(2-24)$ & \\
\hline
\end{tabular}

${ }^{\mathrm{a} A N O V A}$ test was performed to examine p-values for continuous values or categorical values.

LCK:0/10, ppMAPkkk:10/10, MRP3:7/10, PTHrP:8/10, SART2:9/10, SART3:10/10, UBE2V:10/10, WHSC2:10/10 in adenocarcinoma tissues, and Cyp-B:9/10, EGF-R:10/10, EZH2:10/10, HNRPL:10/10, LCK:6/10, ppMAPkkk:8/10, MRP3:1/10, PTHrP:6/10, SART2:10/10, SART3:10/10, UBE2V:10/10, or WHSC2:9/10 in SCC tissues. Lck antigen, a unique vaccine antigen expressed in normal $\mathrm{T}$ cells and a part of metastatic tumor cells $(21,22)$, was expressed in a small fraction of tumor cells in 0 of 10 adenocarcinoma, and 6 of 10 SCC tissues, respectively. None of the three prostate-related antigens (PAP, PSA and PSMA) were detectable in any of these tissues tested (data not shown).

The patient characteristics. Between December 2008 and May 2013, 57 patients with advanced NSCLC were enrolled to this study. Among them, 23 or 16 patients received PPV combined with chemotherapy or targeted therapy, respectively, whereas 18 patients did not tolerate either therapy and received PPV alone. The patient characteristics are shown in Table I. The PPV/targeted therapy group showed younger median age $(p=0.010)$. Median number of previous treatment regimens before PPV in the groups of PPV/chemotherapy, PPV/targeted therapy, or PPV alone were 4,3 or 4 , respectively $(p=0.076)$.
Adverse events. Median times of peptide vaccination were 11, ranging from 2 to 24 times (Table I). Table II shows severe adverse events (SAEs) during the PPV. Nine of 57 patients showed grade 3 SAEs (3 patients each in PPV/chemotherapy, PPV/target therapy and PPV alone group, respectively), and grade 4 SAEs occurred in 4 patients under PPV/chemotherapy. As the vaccination-related adverse events, almost all patients showed grade 1 or 2 dermatological reactions to PPV at the injection sites, but no patients showed SAEs (grade 3 or more) in agreement with previous reports (13-20).

Immune responses. Both peptide-specific CTL and IgG responses were analyzed in blood samples before and after the 1 st cycle of vaccination. CTL responses to the vaccinated peptides were detectable in only 4/52 (7.7\%) patients before vaccination (1, 2 and 1 patients under PPV/chemotherapy, PPV/targeted therapy, or PPV alone, respectively). However, it became detectable after the vaccination in 11/19 (58\%), $7 / 14$ $(50 \%)$, or $5 / 12(42 \%)$ patients in these groups, respectively (Tables III-V). We also tested CTL responses to CEF peptides, a mixture of virus-derived CTL epitopes, as a control. CTL responses to CEF peptides were observed in 14/42 (33.3\%) patients before vaccination, and they were detectable after 
Table II. Severe adverse events (grade 3 or 4) during the PPV.

\begin{tabular}{|c|c|c|c|c|}
\hline & $\begin{array}{c}\text { Overall } \\
\text { (Grade 3/4) }\end{array}$ & $\begin{array}{c}\text { PPV/chemotherapy } \\
\text { (Grade 3/4) }\end{array}$ & $\begin{array}{c}\text { PPV/targeted therapy } \\
\text { (Grade 3/4) }\end{array}$ & $\begin{array}{l}\text { PPV alone } \\
\text { (Grade 3/4) }\end{array}$ \\
\hline \multicolumn{5}{|l|}{ Constitutional symptom } \\
\hline Fever & $1 / 0$ & $0 / 0$ & $0 / 0$ & $1 / 0$ \\
\hline Tumor pain & $1 / 0$ & $0 / 0$ & $1 / 0$ & $0 / 0$ \\
\hline \multicolumn{5}{|l|}{ Respiratory } \\
\hline Dyspnea & $1 / 0$ & $0 / 0$ & $1 / 0$ & $0 / 0$ \\
\hline Hypoxia & $1 / 0$ & $0 / 0$ & $1 / 0$ & $0 / 0$ \\
\hline \multicolumn{5}{|l|}{ Neurological } \\
\hline CNS cerebrovascular ischemia & $0 / 1$ & $0 / 1$ & $0 / 0$ & $0 / 0$ \\
\hline \multicolumn{5}{|l|}{ Blood/bone marrow } \\
\hline Anemia & $1 / 1$ & $0 / 1$ & $0 / 0$ & $1 / 0$ \\
\hline Neutropenia & $0 / 1$ & $0 / 1$ & $0 / 0$ & $0 / 0$ \\
\hline Lymphocytopenia & $2 / 0$ & $1 / 0$ & $1 / 0$ & $0 / 0$ \\
\hline Thrombocytopenia & $1 / 0$ & $1 / 0$ & $0 / 0$ & $0 / 0$ \\
\hline \multicolumn{5}{|l|}{ Metabolic and laboratory } \\
\hline AST increased & $1 / 0$ & $1 / 0$ & $0 / 0$ & $0 / 0$ \\
\hline ALT increased & $1 / 0$ & $1 / 0$ & $0 / 0$ & $0 / 0$ \\
\hline$\gamma$-GTP increased & $1 / 1$ & $0 / 1$ & $0 / 0$ & $1 / 0$ \\
\hline ALP increased & $1 / 0$ & $1 / 0$ & $0 / 0$ & $0 / 0$ \\
\hline
\end{tabular}

PPV, personalized peptide vaccination; CNS, central nervous system; AST, aspartate aminotransferase; ALT, alanine aminotransferase; $\gamma$-GTP, $\gamma$-glutamyl transpeptidase; ALP, alkaline phosphatase.

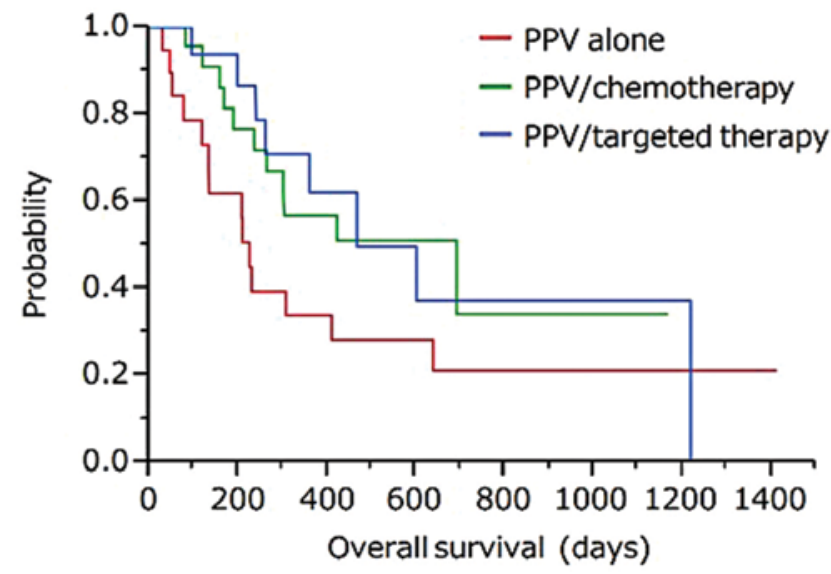

Figure 3. Survival analysis in the three subgroups. Median survival time (MST) was 692, 468, or 226 days in the group of PPV/chemotherapy, PPV/targeted therapy, or PPV alone, respectively. There was no significant difference among the three groups by the log-rank test $(\mathrm{p}=0.2475)$.

vaccination in $6 / 18(33 \%), 3 / 9(33 \%)$, or $6 / 9(67 \%)$ patients in these groups, respectively (data not shown).

Peptide-specific IgG reactive to each of the 31 different peptides, including both vaccinated and non-vaccinated peptides, were measured by bead-based multiplex assay. IgG responses before vaccination were well observed in all the patients. IgG responses specific to at least one of the vacci- nated peptides were increased after vaccination in 31/49 $(63 \%)$ patients tested, with $11 / 20(55 \%), 12 / 16(75 \%)$, or $8 / 13(62 \%)$ patients under PPV/chemotherapy, PPV/targeted therapy, or PPV alone group, respectively (Tables III-V). A greater number of peptides showed IgG responses to HLA-matched nonvaccinated peptides, but not to HLA-non-matched peptides, after vaccination in the PPV/chemotherapy group as compared to those in the PPV alone group ( $\mathrm{p}=0.004)$ (data not shown).

Overall survival. Median survival time (MST) from the first vaccination of PPV was 692, 468, or 226 days in the group of PPV/chemotherapy, PPV/targeted therapy, or PPV alone, respectively (Fig. 3).

\section{Discussion}

It is important to better understand tumor immunity in refractory NSCLC patients who entered this study, since the repeated treatment regimens often suppress antitumor immunity. In addition, $\mathrm{T}$ cell checkpoint molecules, such as CTLA-4, PD-1, and PD-L1, were suggested to inhibit CTL responses against tumor cells in advanced cancer patients (8-11). As expected, CTL responses to the vaccinated peptides, but not to virus-derived peptides, before vaccination were rarely observed ( 1 of 22,2 of 14 , and 1 of 16 patients under PPV/chemotherapy, PPV/targeted therapy, or PPV alone, respectively), indicating antitumor immunity 
Table III. Immune responses to peptides in the PPV/chemotherapy group.

\begin{tabular}{cccc}
\hline $\begin{array}{l}\text { Patient } \\
\text { no. }\end{array}$ & $\begin{array}{c}\text { No. of } \\
\text { vaccinated } \\
\text { peptide }^{\mathrm{a}}\end{array}$ & $\begin{array}{c}\text { No. of peptides } \\
\text { with enhanced } \\
\text { IgG responses }\end{array}$ & $\begin{array}{c}\text { No. of peptides } \\
\text { with enhanced } \\
\text { CTL responses }\end{array}$ \\
\hline 1 & 3 & 0 & 1 \\
2 & 4 & 2 & 0 \\
3 & 4 & 0 & NA \\
4 & 4 & 0 & 1 \\
5 & 4 & NA & NA \\
6 & 4 & 0 & 1 \\
7 & 4 & 1 & 0 \\
8 & 4 & 3 & 1 \\
9 & 4 & 1 & 2 \\
10 & 4 & NA & NA \\
11 & 4 & 2 & 0 \\
12 & 4 & 0 & 1 \\
13 & 4 & 2 & 1 \\
14 & 4 & 0 & 0 \\
15 & 4 & 1 & 0 \\
16 & 4 & 0 & 0 \\
17 & 4 & 0 & 1 \\
18 & 4 & 2 & 0 \\
19 & 4 & NA & NA \\
20 & 4 & 4 & 2 \\
21 & 4 & 2 & 1 \\
22 & 4 & 3 & 0 \\
23 & 4 & 0 & \\
\hline & 4 & & 1 \\
\hline
\end{tabular}

PPV, personalized peptide vaccine; NA, not assessed. ${ }^{\text {aPeptide }}$ numbers used for 1 st cycle of vaccination. ' If the titers of peptidespecific IgG at the end of 1 st cycle were $>2$-fold higher than those in the pre-vaccination plasma, the changes were considered to be enhanced. ${ }^{\mathrm{c}} \mathrm{CTL}$ responses were determined by the number of spots per $10^{5}$ peripheral blood mononuclear cells (PBMCs) reactive with the vaccinated peptides in IFN- $\gamma$ ELISPOT assay before and after $1 \mathrm{st}$ cycle of vaccination.

of these patients was severely depressed. However, CTL responses to the vaccinated peptides became detectable at the end of the 1st cycle (6 or 8 times of vaccination) in 58,50, or $42 \%$ of patients tested in these three groups, respectively. In addition, PPV did not affect CTL responses to virusderived peptides. No PPV-related severe adverse events were observed in any of patients in this study, in agreement with the previous reports (13-20). These results suggest the feasibility of PPV for heavily treated advanced NSCLC patients who failed at least two regimens from the view point of both immunological responses and safety.

MST of patients under PPV/chemotherapy from the first vaccination of PPV was 692 days. Since the MST of the third or fourth line chemotherapy for refractory NSCLC patients was reported to be $\sim 12$ months or $<12$ months, respectively
Table IV. Immune responses to peptides in the PPV/targeted therapy group.

\begin{tabular}{cccc}
\hline $\begin{array}{l}\text { Patient } \\
\text { no. }\end{array}$ & $\begin{array}{c}\text { No. of } \\
\text { vaccinated } \\
\text { peptide }^{\mathrm{a}}\end{array}$ & $\begin{array}{c}\text { No. of peptides } \\
\text { with enhanced } \\
\text { IgG responses }\end{array}$ & $\begin{array}{c}\text { No. of peptides } \\
\text { bith enhanced } \\
\text { CTL responses }\end{array}$ \\
\hline 1 & 4 & 1 & 0 \\
2 & 4 & 1 & 0 \\
3 & 4 & 4 & 2 \\
4 & 4 & 3 & 1 \\
5 & 4 & 1 & 0 \\
6 & 4 & 1 & 2 \\
7 & 3 & 2 & 0 \\
8 & 3 & 1 & 1 \\
9 & 4 & 0 & 2 \\
10 & 3 & 0 & 0 \\
11 & 4 & 1 & 1 \\
12 & 4 & 0 & 0 \\
13 & 4 & 3 & NA \\
14 & 4 & 1 & 1 \\
15 & 4 & 0 & 0 \\
16 & 4 & 2 & NA \\
\hline
\end{tabular}

PPV, personalized peptide vaccine; NA, not assessed. ${ }^{\text {aPeptide }}$ numbers used for 1st cycle of vaccination. 'If the titers of peptidespecific IgG at the end of 1st cycle were >2-fold higher than those in the pre-vaccination plasma, the changes were considered to be enhanced. ${ }^{\mathrm{c}} \mathrm{CTL}$ responses were determined by the number of spots per $10^{5}$ peripheral blood mononuclear cells (PBMCs) reactive with the vaccinated peptides in IFN $-\gamma$ ELISPOT assay before and after $1 \mathrm{st}$ cycle of vaccination.

(23-25), the current data might be promising. MST of patients under PPV/targeted therapy was 468 days, although MST of patients under targeted therapy as the third or fourth line was reported between 6 and 12 months (25-28). MST of patients under PPV alone was 226 days. It is of note that these patients did not tolerate either chemotherapy or targeted therapy, and only best supportive care was applicable for these patients. There are a very few clinical studies for such populations to examine OS, but MST of these patients was reported as $<6$ months (28). Based on the potential clinical benefits and the safety profile, a next step of clinical trial of PPV with or without chemotherapy or targeted therapy would be warranted in heavily treated advanced NSCLC patients.

Based on the biomarker, antigen-specific CTL response was suggested to be a favorable factor in this study, since MST of patients with $(n=11)$ or without $(n=12)$ CTL responses to the vaccinated peptides in the PPV/chemotherapy group was 692 or 305 days, respectively ( $\mathrm{p}=0.1838$ ). Furthermore, MST with or without CTL responses in the PPV alone group was undefined $(\mathrm{n}=5)$ or 210 days $(\mathrm{n}=13)(\mathrm{p}=0.0735)$, respectively. On the contrary, this might be the opposite in antigen-specific $\mathrm{IgG}$ response, since MST of the patients with $(\mathrm{n}=11)$ or without $(n=9)$ increased $\operatorname{IgG}$ responses in the PPV/chemotherapy group 
Table V. Immune responses to peptides in the PPV alone group.

\begin{tabular}{|c|c|c|c|}
\hline $\begin{array}{l}\text { Patient } \\
\text { no. }\end{array}$ & $\begin{array}{c}\text { No. of } \\
\text { vaccinated } \\
\text { peptide }^{\mathrm{a}}\end{array}$ & $\begin{array}{l}\text { No. of peptides } \\
\text { with enhanced } \\
\text { IgG responses }^{b}\end{array}$ & $\begin{array}{l}\text { No. of peptides } \\
\text { with enhanced } \\
\text { CTL responses }\end{array}$ \\
\hline 1 & 4 & 0 & 0 \\
\hline 2 & 4 & 1 & 1 \\
\hline 3 & 4 & 1 & 0 \\
\hline 4 & 4 & NA & NA \\
\hline 5 & 4 & 3 & 1 \\
\hline 6 & 4 & 2 & 1 \\
\hline 7 & 4 & 0 & NA \\
\hline 8 & 4 & NA & NA \\
\hline 9 & 2 & 0 & NA \\
\hline 10 & 4 & 1 & 1 \\
\hline 11 & 4 & NA & NA \\
\hline 12 & 4 & 0 & 0 \\
\hline 13 & 4 & 2 & 0 \\
\hline 14 & 4 & 1 & 1 \\
\hline 15 & 2 & 0 & 0 \\
\hline 16 & 3 & 2 & 0 \\
\hline 17 & 4 & 0 & 0 \\
\hline 18 & 4 & NA & NA \\
\hline
\end{tabular}

PPV, personalized peptide vaccine; NA, not assessed. ${ }^{\text {aPeptide }}$ numbers used for 1 st cycle of vaccination. 'If the titers of peptidespecific IgG at the end of 1 st cycle were $>2$-fold higher than those in the pre-vaccination plasma, the changes were considered to be enhanced. ${ }^{\mathrm{c}} \mathrm{CTL}$ responses were determined by the number of spots per $10^{5}$ peripheral blood mononuclear cells (PBMCs) reactive with the vaccinated peptides in IFN- $\gamma$ ELISPOT assay before and after $1 \mathrm{st}$ cycle of vaccination.

was 302 or 692 days $(\mathrm{p}=0.1093)$, respectively. However, this phenomenon was not observed in patients with PPV alone, since MST of the patients with $(n=8)$ or without $(n=5)$ increased $\operatorname{IgG}$ responses in this group was 321 or 226 days $(\mathrm{p}=0.6305)$, respectively. We previously reported that peptide-specific IgG response was a favorable factor of OS for hormone refractory prostate cancer or other types of patients under PPV $(14,18)$. PPV in those studies, however, was not combined with chemotherapy. We are now addressing the mechanisms involved in such discrepancy in the peptide-specific $\mathrm{IgG}$ responses between the PPV-treated patients with and without combined chemotherapy.

A greater number of peptides showed IgG responses to HLA-matched non-vaccinated peptides after vaccination in the PPV/chemotherapy group as compared to those in the PPV alone group $(p=0.004)$. We previously reported that the epitope spreading assessed by IgG responses to non-vaccinated peptides is a favorable factor for OS of soft-tissue sarcoma patients under PPV (13). Indeed, in the PPV/chemotherapy group, MST of the patients with $(n=10)$ or without $(n=10)$ an increase in IgG responses to non-vaccinated HLA-matched peptides was 692 or 302 days, respectively. Epitope spreading assessed by CTL activity was reported to be associated with clinical responses in some clinical trials $(29,30)$. Chemotherapy-induced tumor cell death could promote antigen presentation by antigen presenting cells to $\mathrm{T}$ cells, which might be in part responsible for the epitope spreading in patients in the PPV/chemotherapy group.

By IHC analysis, 12 out of 15 vaccine antigens, from which the vaccine peptides used for PPV were derived, were expressed in primary NSCLC tissues. Lck antigen, a unique vaccine antigen preferentially expressed both in T cells and metastatic tumor cells $(21,22)$, was expressed in a small fraction of tumor cells in some of SCC tissues. None of the remaining three prostate-related antigens (PAP, PSA and PSMA) were detectable in any of these tissues tested. However, at least PSMA and PAP were reported to be expressed in NSCLC cells (31-33), and PSA was also reported to be expressed in certain types of adenocarcinoma cells (34). Therefore, it could not be emphasized strongly at the present time that none of these prostate related antigens were expressed in tumor cells from NSCLC patients, but peptides derived from these three antigens should be removed from the vaccine peptide candidates in the next PPV for NSCLC patients as reported previously (12).

In conclusion, in a third or fourth line treatment of advanced NSCLC, the PPV, compared with chemotherapy, had a possibility of prolongation of OS. Further evaluation of PPV by prospective randomized trials could be recommended for heavily treated advanced NSCLC.

\section{Acknowledgements}

This study was supported in part by a research program of the Project for Development of Innovative Research on Cancer Therapeutics (P-Direct), Ministry of Education, Culture, Sports, Science and Technology of Japan; a research program of the Regional Innovation Cluster Program of the Ministry of Education, Culture, Sports, Science and Technology of Japan, and a grant from the Sendai Kousei Hospital.

\section{References}

1. Dela Cruz CS, Tanoue LT and Matthay RA: Lung cancer: epidemiology, etiology, and prevention. Clin Chest Med 32: 605-644, 2011.

2. Lu F and Zhang HT: DNA methylation and nonsmall cell lung cancer. Anat Rec 294: 1787-1795, 2011.

3. de Marinis F and Grossi F: Clinical evidence for second- and third-line treatment options in advanced non-small cell lung cancer. Oncologist 13 (Suppl 1): 14-20, 2008.

4. Janku F, Stewart DJ and Kurzrock R: Targeted therapy in non-small-cell lung cancer - is it becoming a reality? Nat Rev Clin Oncol 7: 401-414, 2010.

5. Adjei AA, Mandrekar SJ, Dy GK, et al: Phase II trial of pemetrexed plus bevacizumab for second-line therapy of patients with advanced non-small-cell lung cancer: NCCTG and SWOG study N0426. J Clin Oncol 28: 614-619, 2010.

6. Krzakowski M, Ramlau R, Jassem J, et al: Phase III trial comparing vinflunine with docetaxel in second-line advanced non-small-cell lung cancer previously treated with platinumcontaining chemotherapy. J Clin Oncol 28: 2167-2173, 2010.

7. Okamoto I, Yoshioka H, Morita S, et al: Phase III trial comparing oral S-1 plus carboplatin with paclitaxel plus carboplatin in chemotherapy-naïve patients with advanced non-small-cell lung cancer: results of a west Japan oncology group study. J Clin Oncol 28: 5240-5246, 2010.

8. Brahmer JR, Tykodi SS, Chow LQ, et al: Safety and activity of anti-PD-L1 antibody in patients with advanced cancer. N Engl J Med 366: 2455-2465, 2012. 
9. Lynch TJ, Bondarenko I, Luft A, et al: Ipilimumab in combination with paclitaxel and carboplatin as first-line treatment in stage IIIB/IV non-small-cell lung cancer: results from a randomized, double-blind, multicenter phase II study. J Clin Oncol 30: 2046-2054, 2012.

10. Reck M, Bondarenko I, Luft A, et al: Ipilimumab in combination with paclitaxel and carboplatin as first-line therapy in extensivedisease-small-cell lung cancer: results from a randomized, double-blind, multicenter phase 2 trial. Ann Oncol 24: 75-83, 2013.

11. Topalian SL, Hodi FS, Brahmer JR, et al: Safety, activity, and immune correlates of anti-PD-1 antibody in cancer. $\mathrm{N}$ Engl J Med 366: 2443-2454, 2012.

12. Terasaki M, Shibui S, Narita Y, et al: Phase I trial of a personalized peptide vaccine for patients positive for human leukocyte antigen - A24 with recurrent or progressive glioblastoma multiforme. J Clin Oncol 29: 337-344, 2011.

13. Takahashi R, Ishibashi Y, Hiraoka K, et al: Phase II study of personalized peptide vaccination for refractory bone and soft tissue sarcoma patients. Cancer Sci 104: 1285-1294, 2013.

14. Noguchi M, Kakuma T, Uemura H, et al: A randomized phase II trial of personalized peptide vaccine plus low dose estramustine phosphate (EMP) versus standard dose EMP in patients with castration resistant prostate cancer. Cancer Immunol Immunother 59: 1001-1009, 2010.

15. Terazaki Y, Yoshiyama K, Matsueda S, et al: Immunological evaluation of personalized peptide vaccination in refractory small cell lung cancer. Cancer Sci 103: 638-644, 2012.

16. Noguchi M, Sasada T and Itoh K: Personalized peptide vaccination: a new approach for advanced cancer as therapeutic cancer vaccine. Cancer Immunol Immunother 62: 919-929, 2013.

17. Yoshiyama K, Terazaki Y, Matsueda S, et al: Personalized peptide vaccination in patients with refractory non-small cell lung cancer. Int J Oncol 40: 1492-1500, 2012.

18. Noguchi M, Mine T, Komatsu N, et al: Assessment of immunological biomarkers in patients with advanced cancer treated by personalized peptide vaccination. Cancer Biol Ther 10 $1266-1279,2010$

19. Komatsu N, Shichijo S, Nakagawa M and Itoh K: New multiplexed flow cytometric assay to measure anti-peptide antibody: a novel tool for monitoring immune responses to peptides used for immunization. Scan J Clin Lab Invest 64: 535-545, 2004.

20. Yoshida K, Noguchi M, Mine T, et al: Characteristics of severe adverse events after peptide vaccination for advanced cancer patients: analysis of 500 cases. Oncol Rep 25: 57-62, 2011.

21. Harashima N, Tanaka K, Sasatomi T, et al: Recognition of the Lck tyrosine kinase as a tumor antigen by cytotoxic T lymphocytes of cancer patients with distant metastases. Eur J Immunol 31: 323-332, 2001
22. McCracken S, Kim CS, Xu Y, Minden M and Miyamoto NG: An alternative pathway for expression of p561ck from type I promoter transcripts in colon carcinoma. Oncogene 15: 29292937, 1997.

23. Chen YM, Shih JF, Fan WC, et al: Third-line or fourth-line chemotherapy in non-small-cell lung cancer patients with relatively good performance status. J Chin Med Assoc 74: 209-214, 2011.

24. Asahina H, Sekine I, Horinouchi $\mathrm{H}$, et al: Retrospective analysis of third-line and fourth-line chemotherapy for advanced non-small-cell lung cancer. Clin Lung Cancer 13: 39-43, 2012.

25. Carnio S, Novello S, Mele T, Levra MG and Scagliotti GV: Extending survival of stage IV non-small cell lung cancer. Semin Oncol 41: 69-92, 2014.

26. Mok TS, Lee K and Leung L: Targeting epidermal growth factor receptor in the management of lung cancer. Semin Oncol 41: 101-109, 2014.

27. Langer CJ, Mok T and Postmus PE: Targeted agents in the third-/fourth-line treatment of patients with advanced (stage III/IV) non-small cell lung cancer (NSCLC). Cancer Treat Rev 39: 252-260, 2013.

28. Cromwell I, van der Hoek K, Malfair Taylor SC, Melosky B and Peacock S: Erlotinib or best supportive care for third-line treatment of advanced non-small-cell lung cancer: a real-world cost-effectiveness analysis. Lung Cancer 76: 472-477, 2012.

29. Corbière V, Chapiro J, Stroobant V, et al: Antigen spreading contributes to MAGE vaccination-induced regression of melanoma metastases. Cancer Res 71: 1253-1262, 2011.

30. Pohla H, Buchner A, Stadlbauer B, et al: High immune response rates and decreased frequencies of regulatory $T$ cells in metastatic renal cell carcinoma patients after tumor cell vaccination. Mol Med 18: 1499-1508, 2012.

31. Wang Y, Harada M, Yano H, et al: Prostatic acid phosphatase as a target molecule in specific immunotherapy for patients with nonprostate adenocarcinoma. J Immunother 28: 535-541, 2005.

32. Kinoshita Y, Kuratsukuri K, Landas S, et al: Expression of prostate-specific membrane antigen in normal and malignant human tissues. World J Surg 30: 628-636, 2006.

33. Chang SS, Reuter VE, Heston WD, Bander NH, Grauer LS and Gaudin PB: Five different anti-prostate-specific membrane antigen (PSMA) antibodies confirm PSMA expression in tumorassociated neovasculature. Cancer Res 59: 3192-3198, 1999.

34. Wang Y, Harada M, Yano H, et al: Prostate-specific antigenreactive cytotoxic $\mathrm{T}$ lymphocyte precursors in colon cancer patients. Oncol Rep 15: 317-321, 2006. 